\title{
USF Inhibits Cell Proliferation through Delay in G2/M Phase in FRTL-5 Cells
}

\author{
Hye Seung JUNG, KeUn-SoOK KIM*, Yun JAe CHUNG, Hyun-KYUNG CHUNG**, YonG-Ki MIN, \\ MyUnG-ShIK LEE, MoOn-KyU LEE, KWANG-Won KIM AND JAE HoOn CHUNG
}

\author{
Division of Endocrinology and Metabolism, Department of Medicine, Samsung Medical Center, Sungkyunkwan University School \\ of Medicine, Seoul 135-710, Korea \\ *Samsung Biomedical Research Institute, Seoul 135-710, Korea \\ **Division of Endocrinology and Metabolism, Department of Internal Medicine, Dankook University College of Medicine, Cheonan \\ 330-715, Korea
}

\begin{abstract}
Upstream stimulatory factor (USF) has a negative effect on the cell proliferation in some cell types. However, its effect on thyrocytes is not clear. Therefore, we investigated the effects of USF on the proliferation and function of thyroid follicular cells. Complementary DNAs of the USF-1 and USF-2 were synthesized using RT-PCR from FRTL-5 cells, and each was transfected to FRTL-5 cells and papillary thyroid carcinoma cell lines. Cyclic AMP (cAMP) production and $\left[\right.$ methyl $\left.-{ }^{3} \mathrm{H}\right]$ thymidine uptake after thyroid stimulating hormone $(\mathrm{TSH})$ treatment were measured in FRTL-5 cells. In the carcinoma cell lines, 5-bromo-2'-deoxyuridine (BrdU) uptake was assayed to evaluate cell proliferation. Apoptosis was tested by Hoechst staining and cell cycle analysis was done using a fluorescence activated cell sorting. Expression of cell cycle regulating genes was evaluated by Northern and Western blotting. Overexpression of USF-1 and USF-2 significantly suppressed TSH-stimulated $\left[\right.$ methyl- $\left.{ }^{3} \mathrm{H}\right]$ thymidine uptake $(\mathrm{p}<0.05)$, while it maintained TSH-stimulated cAMP production in FRTL-5 cells. Overexpression of USF significantly suppressed BrdU uptake in each carcinoma cell line, NPA and TPC-1 cells $(p<0.05)$. It induced delay of cell cycle at the $\mathrm{G} 2 / \mathrm{M}$ phase, but did not increase apoptosis in FRTL-5 cells. It was accompanied by a decrease of cyclin B1 and cyclin-dependent kinase (CDK)-1, and an increase of p27 expression. USF-1 and USF-2 suppressed cell proliferation of normal thyrocytes and thyroid carcinoma cells. However, they retained the ability to produce cAMP after TSH stimulation. Their inhibitory effect on cell proliferation might be caused partly by the delay in G2/M phase.
\end{abstract}

Key words: Upstream stimulatory factor (USF), Thyrocyte, Cell proliferation, Cell cycle

(Endocrine Journal 54: 275-285, 2007)

UPSTREAM stimulatory factor (USF) is a transcription factor ubiquitously expressed in most tissues and cell lines $[1,2]$. Two different genes, defined as USF-1 and USF-2, encode the 43 and $44 \mathrm{kDa}$ polypeptides, respectively [3-6]. These two peptides have identical

Received: July 5, 2006

Accepted: December 4, 2006

Correspondence to: Dr. Jae Hoon CHUNG, Division of Endocrinology and Metabolism, Department of Medicine, Samsung Medical Center, Sungkyunkwan University School of Medicine, 50 Ilwon-Dong Gangnam-Gu, Seoul 135-710, Korea

Hye Seung Jung and Keun-Sook Kim contributed equally to this work.
DNA-binding specificities and transcriptional activities $[3-5,7]$. They share a highly conserved C-terminal basic/helix-loop-helix/leucine zipper sequence, which is important to the dimerization and DNA-binding of USF [3, 4, 8-10]. USF is known to inhibit cell proliferation in some cell types [11-14]. The inhibitory effect on the cell proliferation might be accomplished by antagonizing the transforming function of Myc or its binding to promoter sequences as well as specific protein/protein interactions $[13,14]$. This inhibition might be controlled by interactions with a specialized coactivator that recognizes the USF-specific domain region [11]. However, its effect on thyrocytes and the exact mechanism responsible for negative regulation of cell 
proliferation remains unclear. Therefore, we investigated the effects of USF on the proliferation and function of FRTL-5 cells and thyroid carcinoma cells and identified the mechanism responsible for regulation of cell proliferation.

\section{Materials and Methods}

\section{Maintenance of cells}

Fresh F1 subclone of FRTL-5 cells (Interthyr Research Foundation, Baltimore, MD, USA) was grown in $6 \mathrm{H}$ medium. Fresh medium was replaced every 3 days and cells were passed every $7-10$ days. The NPA cell line is a poorly differentiated papillary thyroid carcinoma cell line and was maintained in RPMI 1640. TPC-1 cells, a well-differentiated papillary thyroid carcinoma line, were cultured in Dulbecco's modified Eagle's medium. Both cell lines were obtained from Dr. Minho Shong (Chungnam National University College of Medicine, Daejeon, Korea), and the medium was changed every other day. All cells were grown at $37^{\circ} \mathrm{C}$ in $5 \% \mathrm{CO}_{2}-95 \% \mathrm{O}_{2}$.

\section{Electrophoretic mobility shift assay (EMSA)}

Nuclear proteins from TSH-stimulated and nonstimulated FRTL-5 cells were prepared as described by Suzuki et al. [15]. Protein concentrations were determined using Bio-Rad kit (Hercules, CA, USA). EMSA was performed using $5 \mu \mathrm{g}$ of nuclear extracts. A probe with sodium-iodide symporter (NIS) promoter region ( -2462 to -2429 base pair) was synthesized by labeling with $\left[\gamma^{-32} \mathrm{P}\right]$ ATP and T4 polynucleotide kinase (New England Biolabs). The binding buffer consisted of $20 \mathrm{mM}$ HEPES (pH 7.9), $10 \%$ glycerol, $5 \mathrm{mM} \mathrm{MgCl}_{2}$, $50 \mathrm{mM} \mathrm{KCl}, 1 \mathrm{mM}$ EDTA, $0.1 \%$ Nonidet P-40, and $2 \mu \mathrm{g}$ of poly (dI-dC)-poly (dI-dC). The probe $(50,000$ $\mathrm{cpm}$ ) was added to the nuclear proteins and the sample was incubation for $20 \mathrm{~min}$ at room temperature. DNAprotein complexes were separated through nondenaturated 5\% acrylamide gels at room temperature. Gels were dried and autoradiographed.

\section{Construction of cDNAs and cloning}

Total RNA was extracted from the FRTL-5 cells using an RNA extraction kit (Invitrogen, Carlsbad, CA,
Table 1. Primer sequences of USF-1, USF-2, TTF-1, and Pax-8

\begin{tabular}{|c|c|}
\hline USF-1* & $\begin{array}{l}\text { F 5'-ATGAAGGGGCAGCAGAAAAC-3' } \\
\text { R } 5 \text { 5'-GTTGCTGTCATTCTTGATG-3' }\end{array}$ \\
\hline USF-2 $2^{\dagger}$ & $\begin{array}{l}\text { F 5'-ATGGACATGCTGGACCCGGG-3' } \\
\text { R 5'-CTGCCGGGTACTCTCGCCC-3' }\end{array}$ \\
\hline $\begin{array}{l}\text { TTF- } 1^{*} \\
\text { (homeodomain) }\end{array}$ & $\begin{array}{ll}\text { F } 5 '-A T G C G C C G G A A G C G T C G G G T G C T C-3 ' \\
\text { R } 5 \text { '-CTTCGCCTGGCGCTTCATCTTGTAG-3' }\end{array}$ \\
\hline Pax-8* & $\begin{array}{l}\text { F 5'-ATGCCTCACAACTCGATCAG-3' } \\
\text { R 5'-CAGATGGTCAAAGGCCGTG-3' }\end{array}$ \\
\hline
\end{tabular}

$*$ primer sequence of rat, ${ }^{\dagger}$ primer sequence of mouse

USA), and the amount was measured by spectrophotometer (Pharmacia, Buckinghamshire, England). Two micrograms of RNA mixed with $0.1 \%$ DEPCtreated distilled water were incubated for $5 \mathrm{~min}$ at $70^{\circ} \mathrm{C}$. The cDNA was synthesized using a commercial kit (AccuPower RT PreMix, BiONEER, Daejeon, Korea). PCR for USF-1, -2, Pax-8, and thyroid transcription factor (TTF)-1 was performed in a $20 \mu \mathrm{L}$ reaction mixture containing $5 \mu \mathrm{L}$ of denatured cDNA, $250 \mu \mathrm{M}$ of dNTP mix, $2.5 \mathrm{U}$ of Taq DNA polymerase (BiONEER, Daejeon, Korea), $20 \mathrm{mM}$ of Tris-HCl ( $\mathrm{pH} 8.8$ ), $10 \mathrm{mM}$ of $\mathrm{KCl}, 2 \mathrm{mM}$ of $\mathrm{MgSO}_{4}$ and $0.5 \mu \mathrm{M}$ of each primer (primer sequences for USF-1, -2, Pax-8, and TTF-1 are listed in Table 1). PCR was carried out in a thermal cycler GeneAmp 9600 PCR apparatus (Perkin-Elmer Corp., Norwalk, CT, USA) as follows: initial denaturation at $95^{\circ} \mathrm{C}$ for $5 \mathrm{~min}, 30$ cycles of denaturation $\left(94^{\circ} \mathrm{C}, 1 \mathrm{~min}\right)$, annealing $\left(52\right.$ to $\left.60^{\circ} \mathrm{C}, 1 \mathrm{~min}\right)$, extension $\left(72^{\circ} \mathrm{C}, 2 \mathrm{~min}\right)$ and final extension at $72^{\circ} \mathrm{C}$ for $10 \mathrm{~min}$. The PCR products were electrophoresized in a $1.5 \%$ agarose gel.

The PCR products were purified from the gel using a kit (PCRquick-spin PCR Product Purification Kit, iNtRON Biotechnology, Sungnam, Korea), and then cloned into the pcDNA3.1 vectors using a pcDNA3.1/ V5-His TOPO TA expression kit (Invitrogen, Carlsbad, CA, USA). The cDNA was extracted from a cloned vector using a QIAprep Spin Miniprep kit (QIAGEN Inc., Valencia, CA, USA). Gene sequencing was performed in 2 3 clones for each cDNA using an automated direct sequencing analyzer (ABI PRISM, 377 DNA sequencer, Perkin Elmer, Foster City, CA, USA), and identical clones with references (USF-1, NM_031777; USF-2, NM_011680; Pax8, NM_031141; TTF-1, X_53858) were used for transfection. 


\section{Transfection of cloned cDNA into cells}

\section{FRTL-5 cells}

FuGENE6 (Roche Diagnostics, Mannheim, Germany) was used to transfect DNA plasmids into FRTL-5 cells. The average transfection efficiency into FRTL-5 cells was 15 to $30 \%$.

For cAMP and proliferation assay, FRTL-5 cells were grown to $80 \%$ confluency in $6 \mathrm{H}$ medium and then shifted to $5 \mathrm{H}$ medium (6H medium minus $\mathrm{TSH}$ ) for $3-$ 5 days to make cells quiescent. The cells were transfected with the interested plasmids at a FuGENE6: DNA ratio of $3: 2(\mathrm{vol}: \mu \mathrm{g})$, per the manufacturer's instructions. Twenty-four $\mathrm{h}$ after the outset of transfection, TSH was added to the medium for $24 \mathrm{~h}$ (cAMP assay) or $36 \mathrm{~h}$ (proliferation assay).

For western and cell cycle analysis, FRTL-5 cells were grown to $50-60 \%$ confluence in $6 \mathrm{H}$ medium and then shifted to $0.2 \%$ calf serum $-4 \mathrm{H}$ medium (without $\mathrm{TSH}$, Insulin) for 3 days. Eighteen $\mathrm{h}$ before transfection, the medium was changed to $6 \mathrm{H}$. Then, they were transfected with either the pcDNA3 vector $(5 \mu \mathrm{g})$ or the USF-1,2 expression vector $(5 \mu \mathrm{g})$ plus an expression vector coding for green fluorescent protein $(5 \mu \mathrm{g}$, pEGFP; Clontech, Sydney, Australia) in case of cell cycle analysis. Thirty or fifty hours after transfection with FuGene6, the cells were harvested.

\section{NPA and TPC-1 cells}

For transfection, NPA and TPC-1 cells were incubated with serum free media for $4 \mathrm{~h}$, and then transfected using Lipofectamine Plus (Invitrogen, Carlsbad, CA, USA). After $24 \mathrm{~h}$ of transfection, the cells were fed with complete medium, and after $24 \mathrm{~h}$, cell proliferation was evaluated.

All the transfection experiments were performed in duplicate.

\section{Measurement of cAMP in FRTL-5 cells}

The concentrations of extracellular cAMP were measured using the cAMP EIA system (Amersham Pharmacia Biotech, Piscataway, NJ, USA).

\section{[Methyl- $\left.{ }^{3} \mathrm{H}\right]$ thymidine uptake assay and BrdU incor-} poration

Two $\mu \mathrm{Ci} /$ well of $\left[\right.$ methyl- $\left.{ }^{3} \mathrm{H}\right]$ thymidine (PerkinElmer, Wellesley, MA, USA) were added to medium, and incubated for $6 \mathrm{~h}$. Cells were washed with cold PBS and incubated with 5\% trichloroacetic acid for $20 \mathrm{~min}$ at room temperature. Cells were re-incubated with $0.5 \mathrm{~N} \mathrm{KOH}$ overnight. [Methyl- ${ }^{3} \mathrm{H}$ ] thymidine uptake was counted using a Multi-purpose scintillation counter (Beckman, USA).

In the experiments with carcinoma cell lines, 5bromo-2'-deoxyuridine (BrdU) incorporation was measured using a quantitative ELISA kit (Cell proliferation ELISA, Roche, Germany).

\section{Northern blot analyses}

Total RNA was prepared from FRTL-5 cells either stimulated with TSH $\left(1 \times 10^{-10} \mathrm{M}\right)$ or transfected with USF-1 using a commercial kit (Qiagen Inc., Valencia, CA). Fifteen micrograms of the RNA samples were run on denatured agarose gels, capillary blotted on Nytran membranes, UV cross-linked, and subjected to hybridization. Full length rat USF-1, mouse USF-2, rat $\beta$-actin, rat cyclin B1, and GAPDH were used as probes; radiolabeling was performed as described [15]. Quantitation was performed using a BAS 1500 Bioimaging Analyzer (FUJI Medical Systems USA, Inc., Stamford, CT).

\section{Western blot analysis}

Total proteins were obtained with RIPA buffer supplemented with $\mathrm{NaF}, \mathrm{Na}_{3} \mathrm{VO}_{4}$, PMSF and complete protease inhibitor cocktail tablets (Roche, Germany). Protein concentrations were determined using Bio-Rad kit (Hercules, CA, USA). Twenty micrograms of protein was separated on $10 \%$ SDS-PAGE, transferred to nitrocellulose membranes, blocked in 5\% skim milk, and incubated with antibodies. SuperSignal ${ }^{\circledR}$ West Femto Maximum Sensitivity Substrate (Pierce, Rockford, IL, USA) was used to detect specific bands. All antibodies were from Santa Cruz Biotechnology, Inc. (Santa Cruz, CA, USA); their catalog numbers are as follows: USF-1, sc-229; USF-2, sc-86; p27, sc-528; CDK-1, sc-747; cyclin B1, sc-752; tubulin, sc-5546. Densitometry program used for band intensity measurement was Image Lab (version 2.2.4.0, MCM DESIGN, Denmark).

\section{Cell cycle analysis and Hoechst staining}

The cells were cotransfected with either $5 \mu \mathrm{g}$ of 
pcDNA3.1 vector or $5 \mu \mathrm{g}$ of USF expression vector together with an expression vector coding for green fluorescent protein $(5 \mu \mathrm{g}$, pEGFP; Clontech, Sydney, Australia). Thirty or fifty $\mathrm{h}$ after transfection with FuGENE6, the cells were trypsinized and fixed with $70 \%$ cold ethanol for $12 \mathrm{~h}$ at $4{ }^{\circ} \mathrm{C}$. After washing with PBS, the cells were incubated in PI/RNase staining buffer (BD Biosciences PharMingen) for $10 \mathrm{~min}$ at $37^{\circ} \mathrm{C}$ in the dark. The cells were then subjected to cellcycle analysis employing a FACS Vantage (BD Bioscience, San Jose, CA, USA). GFP-positive cells were gated by fluorescence-activated cell sorting (FACS) prior to assessing the cell-cycle distribution. At least 10,000 GFP-positive events were collected and the data were analyzed using the ModFit LT3.0 software.

Cells with apoptotic bodies were detected by staining with Hoechst 33342 on GFP-containing cells and fluorescence microscopy.

\section{Statistical significance}

All experiments were repeated at least three times with different batches of cells. The data were analyzed using the SPSS-PC software program (version 11.5, Chicago, IL, USA). P values less than 0.05 were considered significant. Statistical significance was determined by two-way analysis of variance (ANOVA) and Student t-test. All values were expressed as mean \pm SD.

\section{Results}

Effects of TSH on the USF binding to NIS promoter and $m R N A$ expression of USF in FRTL-5 cells

$\mathrm{TSH}$, the main hormonal regulator of thyroid function and proliferation, stimulates thyroidal iodide accumulation and NIS gene expression [16, 17]. FRTL-5 cells grown without TSH were treated with $1 \times 10^{-10} \mathrm{M}$ TSH for $24 \mathrm{~h}$, and then nuclear extracts were prepared. In EMSA using NIS promoter as a radiolabeled probe (Fig. 1A), it was clear that TSH decreased USF complex formation.

The ability of TSH to decrease USF binding was associated with a TSH-induced decrease in USF-1 mRNA levels (Fig. 1B). These findings suggested that USF might be associated with TSH-stimulated cell proliferation in the thyrocytes.
A. EMSA

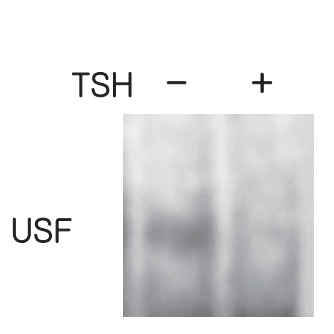

Probe $=$ NIS
B. Northern blot
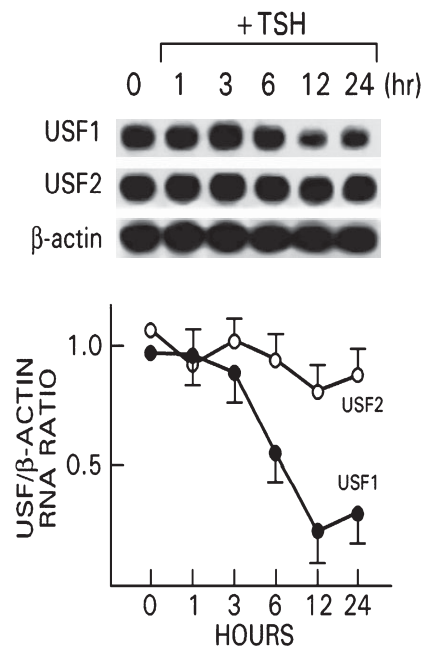

Fig. 1. Inhibitory effect of TSH on the USF binding to NIS promoter and on the USF mRNA levels. (A) FRTL-5 cells were grown to $70 \%$ confluency and maintained in medium without TSH for 5 days before being exposed to $1 \times 10^{-10} \mathrm{M}$ TSH for $48 \mathrm{~h}$. According to EMSA, TSH treatment decreased USF binding to the NIS promoter. (B) FRTL-5 cells were exposed to $1 \times 10^{-10} \mathrm{M}$ TSH for indicated periods. RNA was isolated from each set, and Northern analysis using USF probes was performed. TSH treatment decreased mRNA levels of USF-1 and USF-2 in time-dependent manner.

Effects of USF on the cAMP production and cellular proliferation in FRTL-5 cells

Transient transfection with vectors of some transcription factors induced overexpression of them in FRTL-5 cells. Overexpression of USF was shown in Fig. 6 and 7. Compared to the cells transfected with pcDNA3.1, TSH-stimulated cAMP production was increased with overexpression of USF-1 and USF-2, but TSH-stimulated [methyl- ${ }^{3} \mathrm{H}$ ]-thymidine uptake was significantly decreased ( $p<0.05$, Fig. 2). It means USF enhances the TSH-stimulated cAMP production while suppresses TSH-stimulated cell proliferation. By contrast, overexpression of other thyroid-specific transcription factors, such as TTF-1 and Pax-8, maintained or increased both cAMP production and cell proliferation after TSH stimulation (Fig. 3). Therefore, overexpression of USF-1 or -2 showed different results in thyrocytes compared with known thyroid-specific transcription factors. 


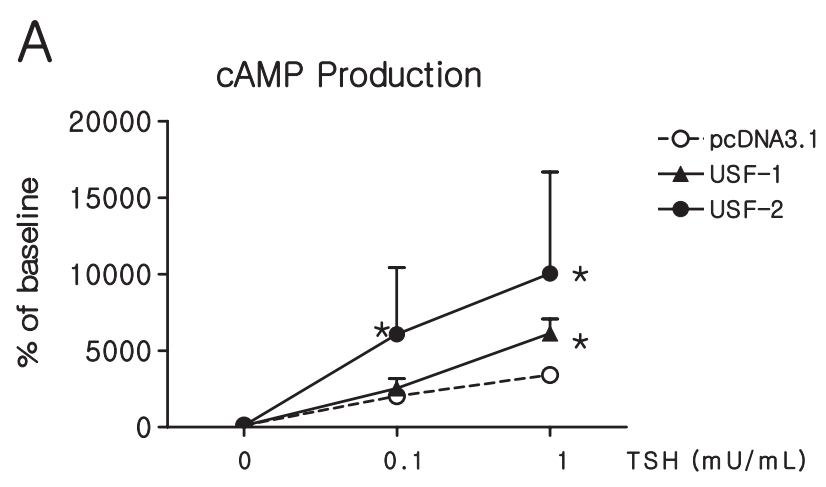

B

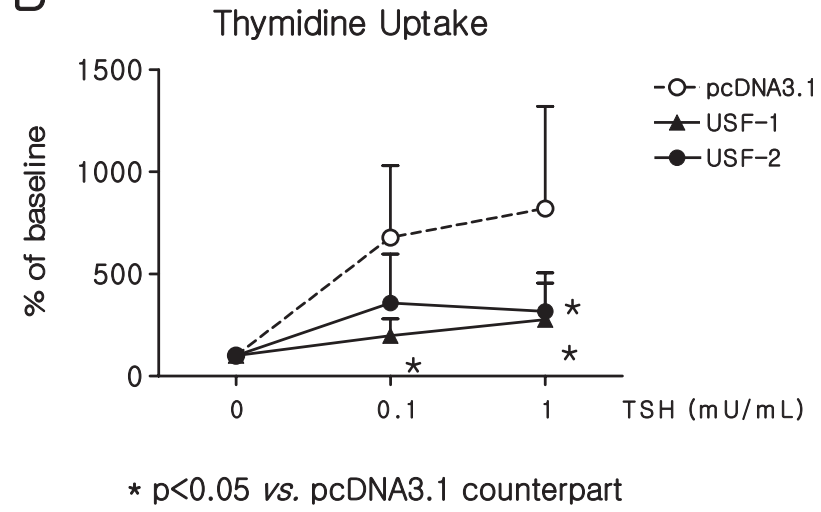

Fig. 2. Effects of USF on the cAMP production (A) and cellular proliferation (B) in FRTL-5 cells. FRTL-5 cells were transfected with USF-1 and USF-2 cDNAs. Transient overexpression of USF significantly increased cAMP production stimulated by serial concentrations $(0.1 \sim 1$ $\mathrm{mU} / \mathrm{mL}$ ) of $\mathrm{TSH}$, but it decreased $\mathrm{TSH}$-stimulated [methyl- ${ }^{3} \mathrm{H}$ ]-thymidine uptake compared to controls $(\mathrm{p}<0.05)$.

Effect of USF on the cellular proliferation in papillary thyroid carcinoma cells

We studied the anti-proliferative effects of USFoverexpression in papillary thyroid carcinoma cells. Transient transfection of transcription factors induced overexpression in papillary thyroid carcinoma. Overexpression of USF-1 and USF-2 significantly decreased BrdU uptake in NPA and TPC-1 cells ( $<<0.05$, Fig. 4). Reduction in BrdU uptake was more prominent in the USF-2-transfected cells $(63 \%$ reduction in NPA, $\mathrm{p}<0.01 ; 49 \%$ reduction in TPC-1, $\mathrm{p}<0.05)$. Overexpression of TTF-1 and Pax-8 had no suppressive effect on the BrdU uptake in these cells (Fig. 4). As a result, we observed that overexpression of USF but not of TTF-1 or Pax-8 suppressed cellular proliferation in papillary thyroid carcinoma cells, as in FRTL-5 cells.
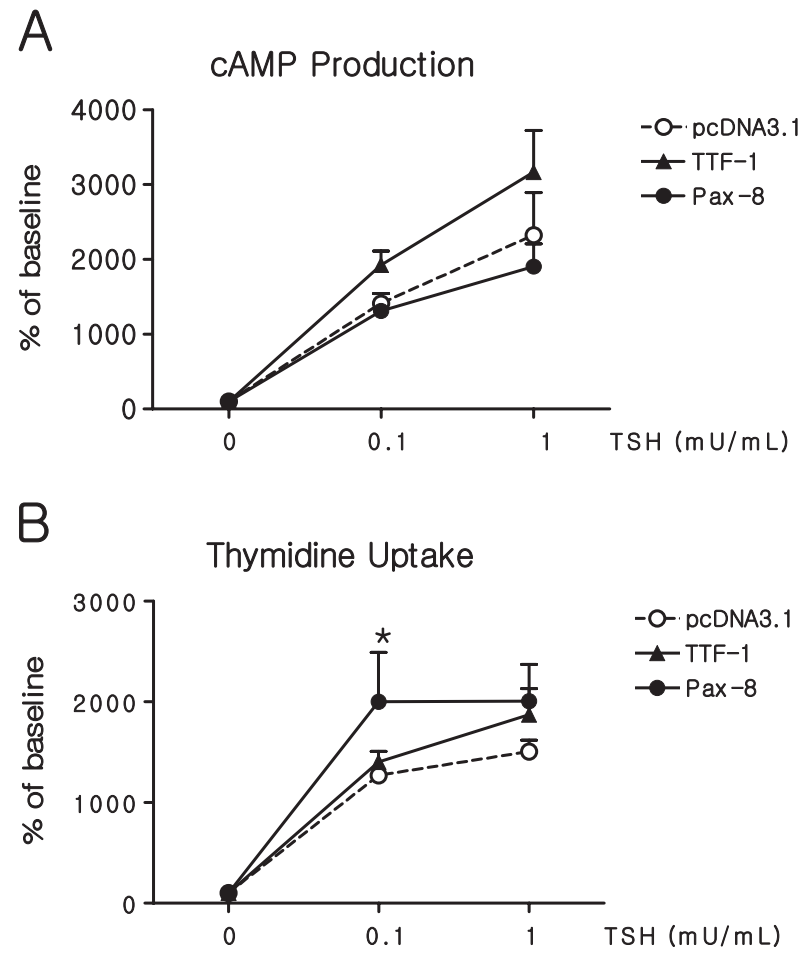

* $p<0.05$ vs. pcDNA3. 1 counterpart

Fig. 3. Effects of TTF- 1 and Pax- 8 on the cAMP production (A) and cellular proliferation (B) in FRTL-5 cells. FRTL-5 cells were transfected with TTF-1 homeodomain and Pax- 8 cDNAs. Transient overexpression of them did not affect cAMP production and [methyl${ }^{3} \mathrm{H}$ ]-thymidine uptake stimulated by serial concentrations $(0.1 \sim 1 \mathrm{mU} / \mathrm{mL})$ of TSH compared to controls. On the contrary, overexpression of the Pax- 8 significantly increased [methyl- ${ }^{3} \mathrm{H}$ ]-thymidine uptake after TSH stimulation $(0.1 \mathrm{mU} / \mathrm{mL})$ compared to control $(\mathrm{p}<0.05)$.

\section{Effect of USF on the apoptosis in FRTL-5 cells}

Apoptosis in FRTL-5 cells that were transfected with USF-1 and USF-2 was evaluated by Hoechst staining. Induction of apoptosis was not observed in the cells with overexpression of USF-1 and USF-2. Therefore, the anti-proliferative effect of USF in thyrocytes was not achieved through apoptosis.

Effects of USF on the cell cycle progression and the cell cycle regulating genes in FRTL-5 cells

FRTL-5 cells were transfected with USF expression vector in conjunction with GFP expression vector. The GFP-positive cells were subjected to cell-cycle analy- 


\section{A. NPA cells}

* $p<0.01$ vs. pcDNA3.1

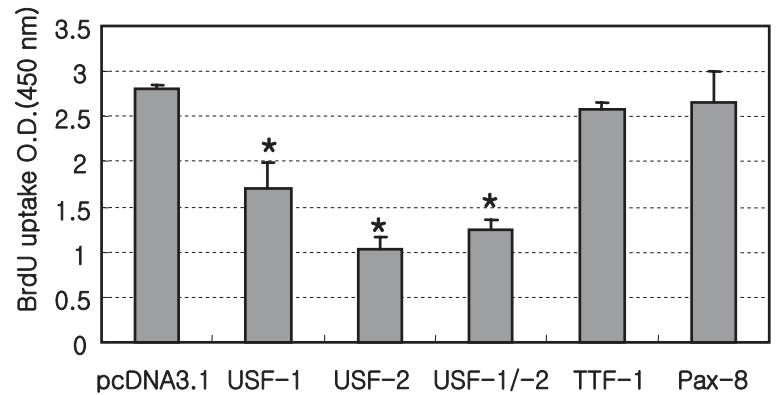

\section{B. TPC-1 cells}

* $p<0.05$ vs. pcDNA3. 1

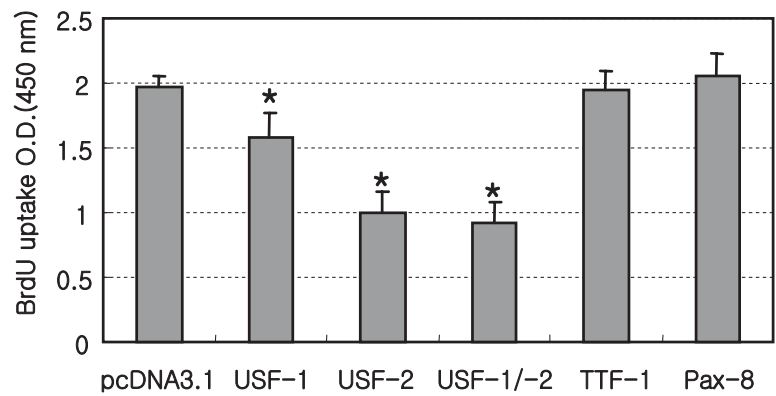

Fig. 4. Effect of USF on the cellular proliferation in papillary thyroid carcinoma cells (A: NPA cells, B: TPC-1 cells). Transient transfection with USF and other transcription factors induced overexpression of them in thyroid papillary carcinoma cell lines. Overexpression of USF-1 and/or USF-2 significantly decreased BrdU uptake in both cell lines ( $<<0.05)$. Reduction in BrdU uptake was more prominent in the cells with overexpression of USF-2. Overexpression of TTF-1 and Pax-8 had no effect on the BrdU uptake in these cells.

sis. Overexpression of USF-1 and USF-2 delayed FRTL-5 cell cycle in G2/M phase. The G2/M phase delay was prominent in the cells incubated for $50 \mathrm{~h}$ after transfection (37\% for pcDNA3.1, 48\% for USF-1, and $52 \%$ for USF-2; Fig. 5) while it was not definite at $30 \mathrm{~h}$ after transfection.

mRNA and the protein expression of cell cycleregulating genes were measured via Northern and Western blotting (Fig. 6 and 7). mRNA expression of cyclin B1 was decreased by overexpression of USF-1. Protein levels of cyclin B1 and CDK1 which are necessary in progression of $\mathrm{G} 2 / \mathrm{M}$ phase were decreased while those of CDK inhibitor, p27 were increased in USF-overexpressed FRTL-5 cells. These results would contribute to the $\mathrm{G} 2 / \mathrm{M}$ phase delay observed in USF-overexpressed FRTL-5 cells.

\section{Discussion}

USF has been reported to inhibit cell proliferation in the rat embryo fibroblast and other cells [11, 13, 14].
Loss of its transcriptional activity has been identified in breast cancer cells [12]. However, the anti-proliferative effect of USF is not common in most cell types. A Saos-2 osteosarcoma cell line was not inhibited in its proliferation by USF [11]. Effects of USF on thyroid follicular cells and thyroid carcinoma cells have not yet been reported. Incidence and prevalence of thyroid cancer is sharply increasing in some countries including Korea [18-21], but there has been no effective preventive method for it. If USF is associated with $\mathrm{TSH}$-stimulated thyrocyte proliferation, it may confer a base for it. Therefore, we investigated the effect and mechanism of USF on TSH-stimulated thyrocyte proliferation.

First, we found that TSH, a potent stimulator of thyroid cell proliferation, decreased mRNA expression and DNA binding of USF (Fig. 1). TSH induces thyroid cellular function and proliferation, as its name suggests. Development of thyroid gland and its functional response to TSH are dependent on the thyroid-specific genes such as thyroglobulin, TSH-receptor, sodiumiodide symporter (NIS), thyroperoxidase, etc. These 
A

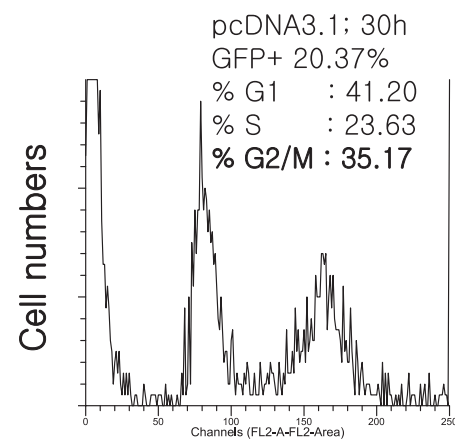

B

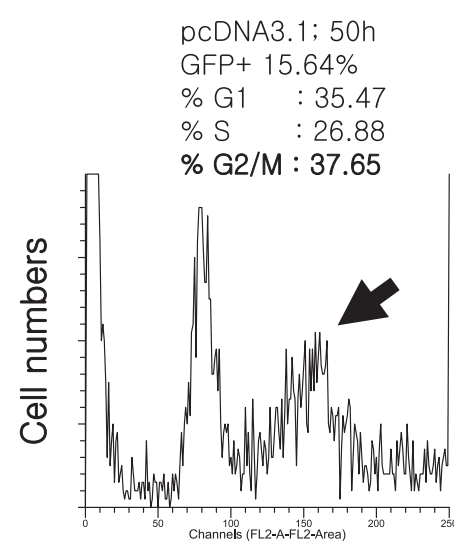


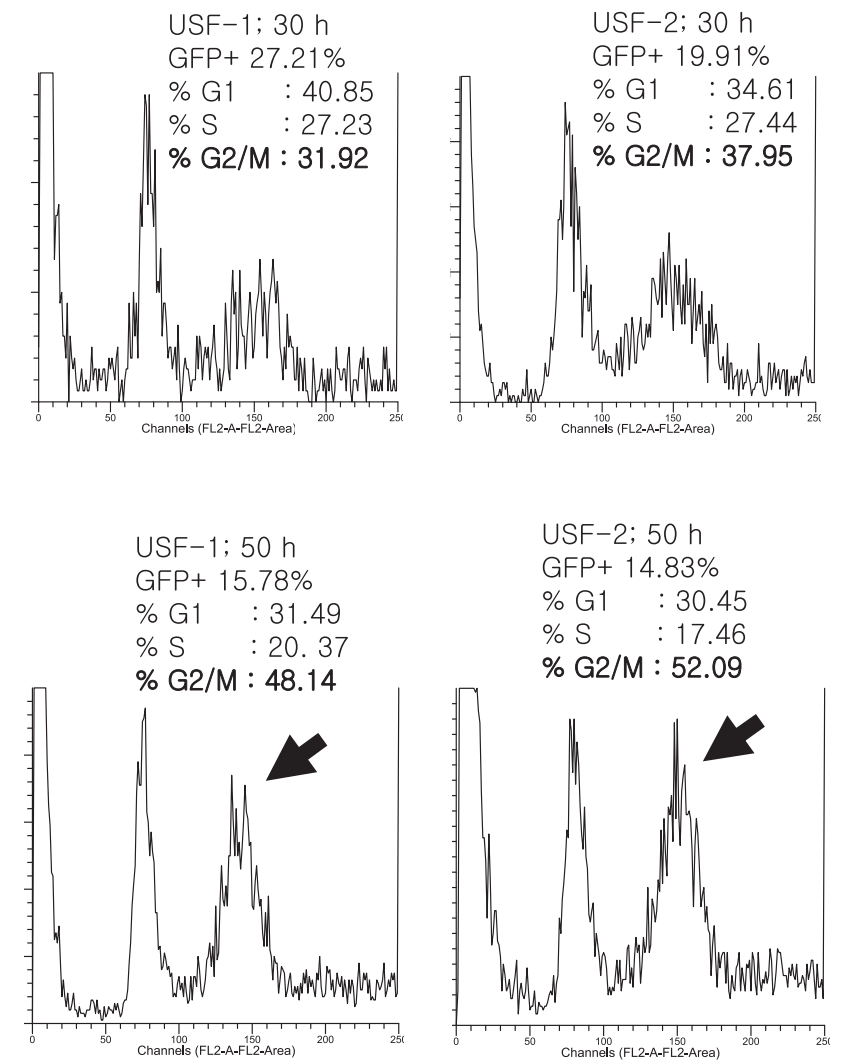

Fig. 5. Effect of USF on the cell cycle progression in FRTL-5 cells. The cells were cotransfected with either pcDNA3.1 vector or USF expression vector together with GFP expression vector. Thirty (A) or 50 (B) h after transfection, GFP-positive cells were gated by FACS and they were subjected to cell-cycle analysis. Overexpression of USF-1 and USF-2 delayed FRTL-5 cell cycle in the G2/M phase. The G2/M phase delay was prominent in the cells incubated for $50 \mathrm{~h}$ after transfection (arrows).

thyroid-specific genes rely on the coordinated action of a master set of transcription factors: the homeodomain protein TTF-1 and the paired-domain protein Pax- 8 [22]. In this study, cAMP (a second messenger of TSH) was measured to evaluate thyroid cellular function after TSH treatment. The effects of USF on the TSH-stimulated cAMP production and cellular proliferation was compared to those of TTF-1 and Pax-8, which are known transcription factors important to both phenomena. As seen in Fig. 2, overexpression of USF-1 and USF-2 increased TSH-stimulated cAMP production, but suppressed TSH-stimulated cell proliferation in FRTL-5 cells. This means that USF overexpression inhibits cell proliferation without impairment of cellular function in thyrocytes. By contrast, overexpression of TTF-1 and Pax-8 maintained cAMP production and cell proliferation after TSH stimulation (Fig. 3). There has been no report on the production of cAMP and USF overexpression directly. Corre et al. showed UV-mediated skin pigmentation through alpha- melanocyte-stimulating hormone and its receptor was mediated by $\mathrm{p} 38$ stress-activated kinase signaling to USF-1 [23]. Alpha-melanocyte-stimulating hormone and its receptor regulate the intracellular levels of cAMP. Therefore, this suggests that USF-1 and cAMP levels have some relationship. In some cell types, USF and cAMP response element-binding protein (CREB) compete the DNA binding $[24,25]$. Therefore, we can speculate that overexpression of USF might inhibit the function of CREB and a feedback mechanism may increase cAMP levels in FRTL-5 cells. This assumption needs further study on the genes that regulate cAMP production in thyroid cells.

The suppressive effect of USF on cell proliferation was also observed in papillary thyroid cancer cell lines, but neither TTF-1 nor Pax-8 suppressed the proliferation of carcinoma cells. These findings suggested that USF-1 and USF- 2 might play a role in the negative regulation of thyroid cell proliferation. USF has been reported to inhibit cell proliferation by antagonizing 




Fig. 6. Effect of USF on the mRNA expression of cyclin B1 gene in FRTL-5 cells. Total RNA was extracted from FRTL- 5 cells transfected with USF-1 cDNAs. mRNA levels of cyclin B1 gene were measured via Northern blotting. Overexpression of USF-1 decreased cyclin B1 expression.

the transforming function of the Myc oncoprotein [14]. Although USF protein shares a similar structure and DNA-binding specificity with Myc, both play antagonistic roles in the control of mammalian cell proliferation [11, 14, 26-28]. USF has also been reported to interfere with Ras-driven transformation and enhance transcriptional activity of p53 [13,29]. The cell typedependent anti-proliferative effect of USF might be achieved through its binding to promoter sequences and specific protein/protein interactions, and this process might be controlled by interaction with a specialized coactivator $[11,13]$. However, the exact mechanism responsible for suppression of cellular proliferation is not clear. From these findings, we speculated that USF might exert an inhibitory effect on cell proliferation through the activation of cell cycle regulatory proteins after binding to its promoter.

USF has been reported to play an important role in gene expression [29-38]. Recently, Cogswell et al. reported that USF-1 binds to a specific site on the cyclin $\mathrm{B} 1$ promoter, and this binding is induced in $\mathrm{G} 2 / \mathrm{M}$ phase-blocked cells [32]. North et al. reported that USF regulated CDC2 (also known as CDK1) gene expression [38]. They suggested that USF might be a G2 phase-specific control protein for cyclin B1 and CDK1. Therefore, we investigated the effects of USF on the progression of the cell cycle, as well as the expression of cell cycle regulatory genes. We performed Hoechst staining to exclude the possibility of apoptosis and then FACS analysis. In this study, we could not observe the induction of apoptosis by USF overexpression. Instead of apoptosis, we observed that USF-1 and USF-2 delayed the FRTL-5 cell cycle in the G2/M phase. Expression of mRNA and proteins regulating the progression of $\mathrm{G} 2 / \mathrm{M}$ phase such as cyclin $\mathrm{B} 1$ and $\mathrm{CDK} 1$ was decreased. But expression of CDK inhibitor such as p27 was increased. These results suggested that both USF-1 and USF-2 inhibit cell proliferation by delay of cell cycle, especially in the G2/M phase, not by apoptosis. The G2/M phase delay was induced by modifying the expression of cyclin B1, CDK1, and p27. Although we did not perform these studies with NPA or TPC-1 cells, the mechanisms by which USF downregulated the cell proliferation in the carcinoma cell lines may be similar to those in FRTL-5 cells. Further evaluation on the mechanisms with NPA or TPC-1 cells will be necessary later.

Phase-specific cyclin-CDK complexes regulate cell cycle progression, which are associated with the synthesis and degradation of specific cyclins. The CDKs are serine/threonine protein kinases that are activated at specific points in the cell cycle [39]. The appropriate dephosphorylation of a specific CDK and its binding to a specific cyclin is necessary for activation. Activated $\mathrm{CDK} 1$ and cyclin $\mathrm{B}$ are required for the transition from $\mathrm{G} 2 / \mathrm{M}$ to the next phase [39-41]. Induction of $\mathrm{G} 2 / \mathrm{M}$ phase delay is thought to occur mainly by phosphorylation of CDK1. Wee1 protein kinase phosphorylates and inactivates CDK1, but CDC25C phosphatase dephosphorylates and activates it $[39,42-48]$. The p21 family includes p21 (also known as waf1, cip1, and pic1), p27 (kip1), and p57 (kip2) [39, 48, 49]. The p27 inhibits most CDKs and is of primary importance in the regulation of G1 phase $[39,50]$. However, the p27 has been implicated in $\mathrm{G} 2$ delay in a variety of cell types [51-53]. The p27 as well as Wee1 appear to play a role in $\mathrm{G} 2 / \mathrm{M}$ phase delay in some cells. 

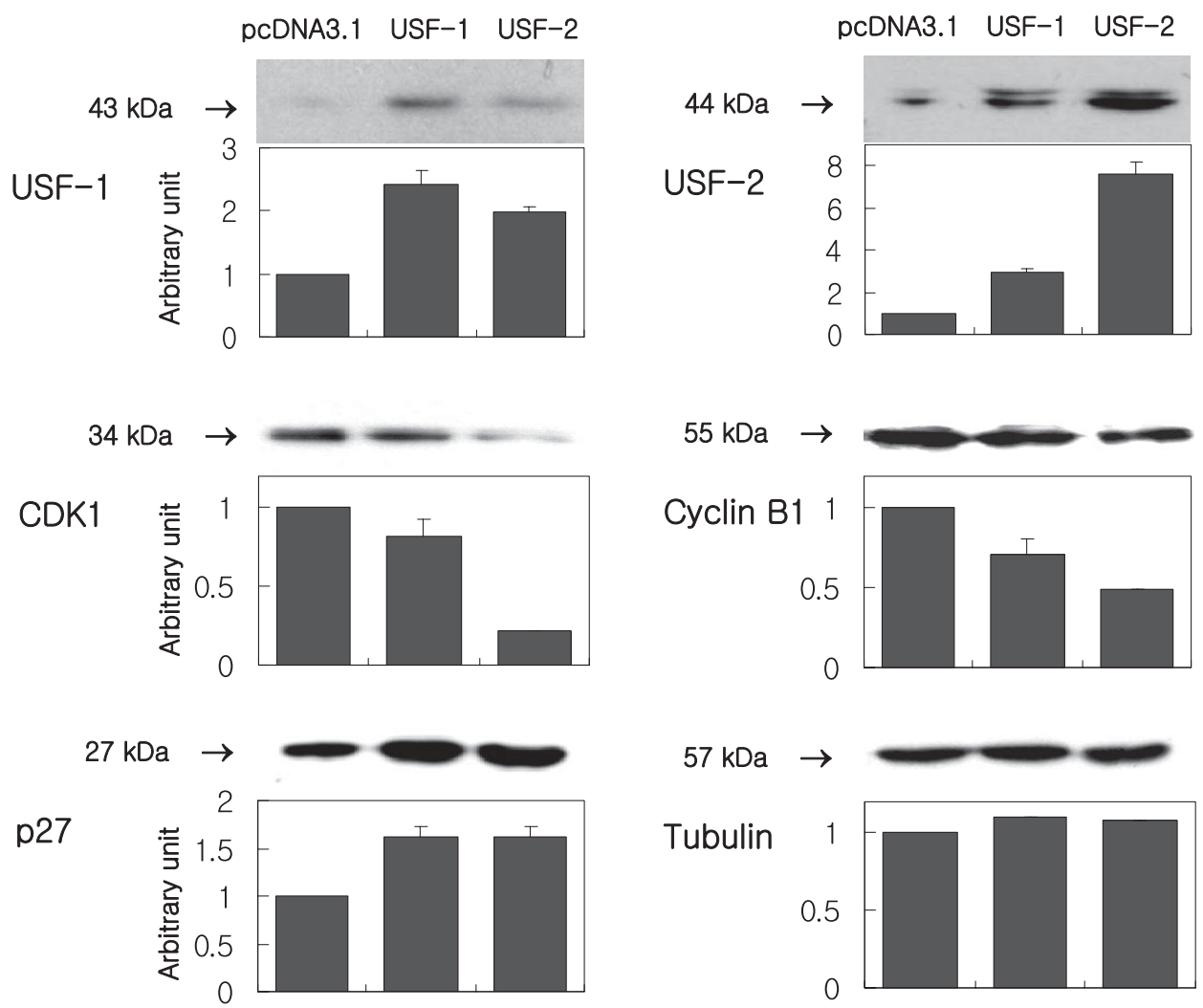

Fig. 7. Effect of USF on the protein expression of cell cycle-regulating genes in FRTL-5 cells. Protein was extracted from FRTL-5 cells transiently transfected with either USF-1 or USF-2 cDNAs. Protein levels of cell cycle-regulating genes were measured via western blotting. Overexpression of USF-1 and USF-2 decreased CDK1 and Cyclin B1. On the contrary, it increased the protein levels of $\mathrm{p} 27$, a CDK inhibitor.

In summary, our findings suggested that both USF-1 and USF-2 played a role in suppressing the cell proliferation of normal thyrocytes and papillary thyroid carcinoma cells. However, they retained the ability to produce cAMP after TSH stimulation. Their antiproliferative effects could be ascribed to $\mathrm{G} 2 / \mathrm{M}$ phase delay by modifying the expression of cell-cycle regulating proteins.

\section{Acknowledgement}

This work was supported by the Samsung Biomedical Research Institute grant, \#SBRI C-A3-226-2, C-A5332-1, and C-A6-426-1.

\section{References}

1. Sawadogo M, Roeder RG (1985) Interaction of a genespecific transcription factor with the adenovirus major late promoter upstream of the TATA box region. Cell 43: 165-175.

2. Carthew RW, Chodosh LA, Sharp PA (1985) An RNA polymerase II transcription factor binds to an upstream element in the adenovirus major late promoter. Cell 43: 439-448.

3. Gregor PD, Sawadogo M, Roeder RG (1990) The adenovirus major late transcription factor USF is a member of the helix-loop-helix group of regulatory proteins and binds to DNA as a dimer. Genes Dev 4: 1730-1740.

4. Sirito M, Walker S, Lin Q, Kozlowski MT, Klein WH, Sawadogo M (1992) Members of the USF family of helix-loop-helix proteins bind DNA as homo- as well as heterodimers. Gene Expr 2: 231-240.

5. Sirito M, Lin Q, Maity T, Sawadogo M (1994) Ubiqui- 
tous expression of the 43- and 44-kDa forms of transcription factor USF in mammalian cells. Nucleic Acids Res 22: 427-433.

6. Sawadogo M, Van Dyke MW, Gregor PD, Roeder RG (1988) Multiple forms of the human gene-specific transcription factor USF. I. Complete purification and identification of USF from HeLa cell nuclei. $J$ Biol Chem 263: 11985-11993.

7. Sawadogo M (1988) Multiple forms of the human gene-specific transcription factor USF. II. DNA binding properties and transcriptional activity of the purified HeLa USF. J Biol Chem 263: 11994-12001.

8. Kirschbaum BJ, Pognonec P, Roeder RG (1992) Definition of the transcriptional activation domain of recombinant 43-kilodalton USF. Mol Cell Biol 12: 5094 5101.

9. Pognonec P, Roeder RG (1991) Recombinant 43-kDa USF binds to DNA and activates transcription in a manner indistinguishable from that of natural 43/44kDa USF. Mol Cell Biol 11: 5125-5136.

10. Luo X, Sawadogo M (1996) Functional domains of the transcription factor USF2: atypical nuclear localization signals and context-dependent transcriptional activation domains. Mol Cell Biol 16: 1367-1375.

11. Qyang Y, Luo X, Lu T, Ismail PM, Krylov D, Vinson C, Sawadogo M (1999) Cell-type-dependent activity of the ubiquitous transcription factor USF in cellular proliferation and transcriptional activation. Mol Cell Biol 19: 1508-1517.

12. Ismail PM, Lu T, Sawadogo M (1999) Loss of USF transcriptional activity in breast cancer cell lines. Oncogene 18: 5582-5591.

13. Aperlo C, Boulukos KE, Pognonec P (1996) The basic region/helix-loop-helix/leucine repeat transcription factor USF interferes with Ras transformation. Eur $J$ Biochem 241: 249-253.

14. Luo X, Sawadogo M (1996) Antiproliferative properties of the USF family of helix-loop-helix transcription factors. Proc Natl Acad Sci USA 93: 1308-1313.

15. Suzuki K, Lavaroni S, Mori A, Okajima F, Kimura S, Katoh R, Kawaoi A, Kohn LD (1998) Thyroid transcription factor 1 is calcium modulated and coordinately regulates genes involved in calcium homeostasis in C cells. Mol Cell Biol 18: 7410-7422.

16. Dai G, Levy O, Carrasco N (1996) Cloning and characterization of the thyroid iodide transporter. Nature 379 : 458-460.

17. Carrasco N (1993) Iodide transport in the thyroid gland. Biochim Biophys Acta 1154: 65-82.

18. Davies L, Welch HG (2006) Increasing incidence of thyroid cancer in the United States, 1973-2002. JAMA 295: 2164-2167.

19. Leenhardt L, Grosclaude P, Cherie-Challine L (2004) Increased incidence of thyroid carcinoma in france: a true epidemic or thyroid nodule management effects?
Report from the French Thyroid Cancer Committee. Thyroid 14: 1056-1060.

20. Shin HR, Won YJ, Jung KW, Kong HJ, Yim SH, Lee JK, Noh HI, Pisani P, Park JG, Ahn YO, Lee SY, Lee CW, Woo ZH, Lee TY, Choi JS, Yoo CI, Bae JM (2005) Nationwide Cancer Incidence in Korea, 1999 2001; First Result Using the National Cancer Incidence Database. Cancer Res Treat 37: 325-331.

21. Lee SJ, Shin MH, Choi JS (2006) A study on the incidence of cancer and evaluating the quality of the community-based cancer registry in Gwangju Metropolitan City during the first five years of implementation (1998-2002). J Prev Med Pub Health 39: 255-262.

22. Christophe D (2004) The control of thyroid-specific gene expression: what exactly have we learned as yet? Mol Cell Endocrinol 223: 1-4.

23. Corre S, Primot A, Sviderskaya E, Bennett DC, Vaulont S, Goding CR, Galibert MD (2004) UV-induced expression of key component of the tanning process, the POMC and MC1R genes, is dependent on the p-38activated upstream stimulating factor-1 (USF-1). J Biol Chem 279: 51226-51233.

24. Tabuchi A, Sakaya H, Kisukeda T, Fushiki H, Tsuda M (2002) Involvement of an upstream stimulatory factor as well as cAMP-responsive element-binding protein in the activation of brain-derived neurotrophic factor gene promoter I. J Biol Chem 277: 35920-35931.

25. Steiger JL, Bandyopadhyay S, Farb DH, Russek SJ (2004) cAMP response element-binding protein, activating transcription factor-4, and upstream stimulatory factor differentially control hippocampal GABABR1a and GABABR1b subunit gene expression through alternative promoters. J Neurosci 24: 6115-6126.

26. Kerkhoff E, Bister K, Klempnauer KH (1991) Sequence-specific DNA binding by Myc proteins. Proc Natl Acad Sci USA 88: 4323-4327.

27. Bendall AJ, Molloy PL (1994) Base preferences for DNA binding by the bHLH-Zip protein USF: effects of $\mathrm{MgCl} 2$ on specificity and comparison with binding of Myc family members. Nucleic Acids Res 22: 28012810.

28. Blackwell TK, Kretzner L, Blackwood EM, Eisenman RN, Weintraub H (1990) Sequence-specific DNA binding by the c-Myc protein. Science 250: 1149-1151.

29. Reisman D, Rotter V (1993) The helix-loop-helix containing transcription factor USF binds to and transactivates the promoter of the p53 tumor suppressor gene. Nucleic Acids Res 21: 345-350.

30. Weigert C, Brodbeck K, Sawadogo M, Haring HU, Schleicher ED (2004) Upstream stimulatory factor (USF) proteins induce human TGF-beta1 gene activation via the glucose-response element-1013/-1002 in mesangial cells: up-regulation of USF activity by the hexosamine biosynthetic pathway. J Biol Chem 279: 15908-15915. 
31. Scholtz B, Kingsley-Kallesen M, Rizzino A (1996) Transcription of the transforming growth factor-beta2 gene is dependent on an E-box located between an essential cAMP response element/activating transcription factor motif and the TATA box of the gene. $J$ Biol Chem 271: 32375-32380.

32. Cogswell JP, Godlevski MM, Bonham M, Bisi J, Babiss L (1995) Upstream stimulatory factor regulates expression of the cell cycle-dependent cyclin B1 gene promoter. Mol Cell Biol 15: 2782-2790.

33. Qian J, Kaytor EN, Towle HC, Olson LK (1999) Upstream stimulatory factor regulates $\mathrm{Pdx}-1$ gene expression in differentiated pancreatic beta-cells. Biochem $J$ 341 ( Pt 2): 315-322.

34. Zhong G, Fan T, Liu L (1999) Chlamydia inhibits interferon gamma-inducible major histocompatibility complex class II expression by degradation of upstream stimulatory factor 1. J Exp Med 189: 1931-1938.

35. Jaiswal AS, Narayan S (2001) Upstream stimulating factor-1 (USF1) and USF2 bind to and activate the promoter of the adenomatous polyposis coli (APC) tumor suppressor gene. J Cell Biochem 81: 262-277.

36. Howcroft TK, Murphy C, Weissman JD, Huber SJ, Sawadogo M, Singer DS (1999) Upstream stimulatory factor regulates major histocompatibility complex class I gene expression: the U2DeltaE4 splice variant abrogates E-box activity. Mol Cell Biol 19: 4788-4797.

37. Lanigan TM, Russo AF (1997) Binding of upstream stimulatory factor and a cell-specific activator to the calcitonin/calcitonin gene-related peptide enhancer. $J$ Biol Chem 272: 18316-18324.

38. North S, Espanel X, Bantignies F, Viollet B, Vallet V, Jalinot P, Brun G, Gillet G (1999) Regulation of cdc2 gene expression by the upstream stimulatory factors (USFs). Oncogene 18: 1945-1955.

39. Schafer KA (1998) The cell cycle: a review. Vet Pathol 35: 461-478.

40. Nurse P (1990) Universal control mechanism regulating onset of M-phase. Nature 344: 503-508.

41. Morgan DO (1997) Cyclin-dependent kinases: engines, clocks, and microprocessors. Annu Rev Cell Dev Biol 13: 261-291.
42. Parker LL, Piwnica-Worms H (1992) Inactivation of the p34cdc2-cyclin B complex by the human WEE1 tyrosine kinase. Science 257: 1955-1957.

43. Heald R, McLoughlin M, McKeon F (1993) Human wee1 maintains mitotic timing by protecting the nucleus from cytoplasmically activated $\mathrm{Cdc} 2$ kinase. Cell 74: 463-474.

44. McGowan CH, Russell P (1993) Human Wee1 kinase inhibits cell division by phosphorylating p34cdc2 exclusively on Tyr15. EMBO J 12: 75-85.

45. Mueller PR, Coleman TR, Kumagai A, Dunphy WG (1995) Myt1: a membrane-associated inhibitory kinase that phosphorylates $\mathrm{Cdc} 2$ on both threonine-14 and tyrosine-15. Science 270: 86-90.

46. Kornbluth S, Sebastian B, Hunter T, Newport J (1994) Membrane localization of the kinase which phosphorylates p34cdc2 on threonine 14. Mol Biol Cell 5: 273282.

47. McGowan CH, Russell P (1995) Cell cycle regulation of human WEE1. EMBO J 14: 2166-2175.

48. Toyoshima H, Hunter T (1994) p27, a novel inhibitor of G1 cyclin-Cdk protein kinase activity, is related to p21. Cell 78: 67-74.

49. Xiong Y (1996) Why are there so many CDK inhibitors? Biochim Biophys Acta 1288: 1-5.

50. Resnitzky D, Hengst L, Reed SI (1995) Cyclin Aassociated kinase activity is rate limiting for entrance into $\mathrm{S}$ phase and is negatively regulated in G1 by p27Kip1. Mol Cell Biol 15: 4347-4352.

51. Roublevskaia IN, Polevoda BV, Ludlow JW, Haake AR (2000) Induced G2/M arrest and apoptosis in human epidermoid carcinoma cell lines by semisynthetic drug Ukrain. Anticancer Res 20: 3163-3167.

52. Hashimoto $\mathrm{O}$, Ueno $\mathrm{T}$, Kimura $\mathrm{R}$, Ohtsubo $\mathrm{M}$, Nakamura T, Koga H, Torimura T, Uchida S, Yamashita K, Sata M (2003) Inhibition of proteasome-dependent degradation of Wee1 in G2-arrested Hep3B cells by TGF beta 1. Mol Carcinog 36: 171-182.

53. Font dM, Uren A, Heidaran M, Santos E (1997) Biological activity of p27kip1 and its amino- and carboxyterminal domains in G2/M transition of Xenopus oocytes. Oncogene 15: 2541-2551. 